\title{
Laboreal
}

Volume 15 N$^{\circ} 2$ | 2019

Varia

\section{Subjetividade e trabalho : entre mal-estar e bem- estar : apresentação do dossier}

Subjetividad y trabajo : entre malestar y bienestar : presentación del dossier Subjectivité et travail : entre inconfort et bien-être : présentation du dossier Subjectivity and work : between discomfort and well-being : presentation of the dossier

Dominique Lhuilier e Marianne Lacomblez

\section{OpenEdition}

\section{Journals}

\section{Edição electrónica}

URL: http://journals.openedition.org/laboreal/15294

DOI: 10.4000/laboreal.15294

ISSN: 1646-5237

\section{Editora}

Universidade do Porto

\section{Refêrencia eletrónica}

Dominique Lhuilier e Marianne Lacomblez, « Subjetividade e trabalho : entre mal-estar e bem-estar apresentação do dossier », Laboreal [Online], Volume 15 №2 | 2019, posto online no dia 01 dezembro 2019, consultado o 24 setembro 2020. URL : http://journals.openedition.org/laboreal/15294 ; DOI : https://doi.org/10.4000/laboreal.15294

Este documento foi criado de forma automática no dia 24 setembro 2020.

\section{(c) (i) (9)}

Laboreal está licenciado com uma Licença Creative Commons - Atribuição-NãoComercial 4.0 Internacional. 


\title{
Subjetividade e trabalho : entre mal- estar e bem-estar : apresentação do dossier
}

\author{
Subjetividad y trabajo : entre malestar y bienestar : presentación del dossier \\ Subjectivité et travail : entre inconfort et bien-être : présentation du dossier \\ Subjectivity and work : between discomfort and well-being : presentation of the \\ dossier
}

Dominique Lhuilier e Marianne Lacomblez

\section{0 simpósio de Havana}

1 Decorreu em Havana, de 29 a 31 de Outubro de 2018, um simpósio "França-América Latina" subordinado ao tema: Subjetividade e trabalho: entre mal-estar e bem-estar. Construção de um novo paradigma de saúde no trabalho.

2 Este evento tinha como objetivo reforçar as formas de cooperação entre diversos organismos, instituições e investigadores que, de longa data, vêm trabalhando em vários países para a promoção da saúde dos trabalhadores, quer com a produção de trabalhos científicos quer com o desenvolvimento de ações de prevenção nos diferentes contextos laborais. Assim, a organização do simpósio esteve a cargo do Instituto Nacional para a Saúde dos Trabalhadores (Cuba) e de várias universidades, não só cubanas, mas também argentinas, brasileiras, chilenas e francesas. O Simpósio contou ainda com a colaboração de diversos parceiros ligados a este tema: SELF, AFPTO, INSAT, RIPSIT, CYTED, a rede TAS, RESPTO, GESTES ${ }^{1}$.

3 Foi assim que investigadores e especialistas oriundos de contextos sócio-culturais distintos (Argentina, Brasil, Chile, Colômbia, Cuba, Uruguai, França, Portugal, Quebeque e Suíça), com diferentes experiências profissionais, mas todos empenhados num objetivo comum de humanização do trabalho, colaboraram durante esses três dias: 
mais de 450 participantes e 181 comunicações (41 em espanhol, 75 em português e 65 em francês).

Este dossier, publicado pela revista Laboreal, não pretende nem pode dar conta do vasto número de temas e debates dessas jornadas ${ }^{2}$. Optou-se, assim, por apresentar aqui algumas contribuições que revelam o desenvolvimento da psico(socio)logia no domínio da saúde no trabalho e, igualmente, da medicina do trabalho.

Reúnem-se, deste modo, cinco artigos que, tendo como base as respetivas comunicações apresentadas no simpósio, propõem análises contextualizadas da investigação e de ações levadas a cabo na Argentina, no Brasil, no Chile, na Colômbia e em Cuba.

\section{Balanço da construção de um novo paradigma de saúde no trabalho}

6 A problemática escolhida privilegia a análise das relações entre trabalho e saúde baseada em comparações internacionais e estudos pluridisciplinares. Abordar a relação saúde/trabalho pressupõe a clarificação dos conceitos de ambos os termos e das suas recíprocas relações. Mas, se se impõe clarificar os termos no plano do conhecimento científico, no plano da ação o problema é igualmente relevante. Além disso, tais questões têm de ser necessariamente repostas nos contextos económicos, políticos, sociais e culturais de cada país.

7 Embora a tarefa seja complexa e as situações diversas, há algumas linhas de reflexão comuns que emergem dos diferentes intercâmbios que, por sua vez, permitem esboçar uma trama para os próximos encontros - e que pretendemos sistematizar aqui :

8 2.1. Tanto no sentido comum como em aceções científicas, o termo trabalho é polissémico. Quando se confunde com a tarefa definida ou com a profissão, a dimensão da atividade real desaparece completamente. Por outro lado, a tónica na atividade pode acabar por subestimar a divisão social do trabalho, as relações sociais de trabalho ou as normas jurídicas previstas para as enquadrar. Além do mais, em muitos países, aquilo a que chamamos trabalho informal (fora de qualquer relação contratual estabelecida) corresponde a uma parte fundamental da produção e das condições de vida da população trabalhadora. Isto obriga a rever as conceções do trabalho essencialmente relacionadas com a esfera do emprego (por exemplo, como conceber a relação tarefa/ atividade nesses contextos laborais ?).

9 2.2. As comparações internacionais podem levar a repensar a assimilação do trabalho ao emprego. Elas podem ajudar a ter em conta outros tipos de atividades para além das que assentam no assalariamento. Há inúmeras atividades que asseguram as mesmas funções que o trabalho, entendido no sentido comum do termo : função utilitária, social e identitária. Esta perspetiva reassocia a vida de trabalho com a vida fora do trabalho para levar em conta os processos de interação no âmbito do sistema das atividades, da sua regulação e desregulação. A relação laboral e as atividades nela desenvolvidas, mais do que caracterizarem uma esfera autónoma, fundem-se com toda a vida passada e atual. São, precisamente, essas atividades desenvolvidas no âmbito do trabalho e fora dele que constituem, com o correr dos tempos, conhecimentos e modos de saber-fazer que podem ser transferidos duma esfera para a outra. Esta questão prende-se sobretudo com as questões de género. 
10 2.3. Mesmo quando considerada a atividade (enquadrada ou não na subordinação constitutiva dum contrato de trabalho), o trabalho pode também designar coisas muito diferentes, por exemplo: uma "atividade inconsciente", semelhante à do operário taylorista ; ou uma atividade laboral sempre única, embora fundamentalmente ligada à atividade dos outros, sobretudo através do coletivo de trabalho, um instrumento da atividade individual. $\mathrm{Na}$ verdade, atividade e subjetividade não são dissociáveis, considerando-se a subjetividade quer nas suas relações com os quadros simbólicos que orientam o sentido quer nas suas relações inevitáveis com a corporalidade.

11 2.4. A relação entre saúde e trabalho está envolvida em profundas controvérsias epistemológicas e simultaneamente em questões sociais igualmente importantes, tanto na América Latina como no Canadá e na Europa. É sabido que a perceção da relação entre saúde e trabalho se construiu historicamente através do prisma doença e trabalho, e que os efeitos deletérios do trabalho na saúde são há muito tempo objeto de preocupação. São essas primeiras análises sobre a natureza da relação entre saúde e trabalho que estão na base dos trabalhos atuais que analisam as doenças próprias de cada oficio, ou os danos para a saúde do novo trabalho industrial que conjuga exploração e miséria. E também estiveram na base das intervenções dos movimentos sociais e do próprio Estado que marcaram a história de uma herança memorável : uma herança materializada no sistema atual, atravessada por uma combinação de lutas, mobilizações, inquéritos, legislações e instituições, e que tiveram por objetivo a prevenção e o ressarcimento dos danos causados pelo trabalho.

12 No entanto, essas abordagens da saúde no trabalho têm de ser reapreciadas à luz dos atuais contextos sociais, históricos e culturais de países com diferentes referenciais, diferentes regulamentações e diferentes sistemas de avaliação da saúde dos trabalhadores.

13 2.5. O esquema determinista causa-efeito, que durante muito tempo dominou a abordagem das patologias profissionais, pode ainda prevalecer, designadamente em Cuba, onde os colegas esperavam deste Simpósio a possibilidade de se inserir na dinâmica da construção de um novo paradigma da saúde no trabalho. Trata-se, na realidade, de tornar o modelo inicial mais complexo para integrar abordagens multifactoriais e diacrónicas; por exemplo: ter em conta a associação e a potencialização de riscos ; considerar o período de latência entre a exposição aos riscos e as manifestações clínicas ; reconstituir as trajetórias de exposição a situações nocivas. Reavaliar-se-á, assim, a hipótese patogénica, inspirada no modelo da toxicologia clássica, à luz de uma abordagem aberta à complexidade das histórias profissionais reais. Podemos, então, considerar uma revisão da noção de nocividade do trabalho, salientando as desigualdades em relação ao risco, dado que as condições sócioeconómicas que caracterizam a vida das/dos que trabalham (estado nutricional, educação, possibilidade de acesso à informação, qualidade concreta/real das políticas públicas, alojamento, ...) podem decuplicar os efeitos da exposição a 'fatores de risco' nocivos. É, portanto, por razões científicas, e não apenas éticas ou políticas, que se impõe uma abordagem 'integrada', multi-profissional e interdisciplinar.

14 2.6. Acresce ainda que essa problematização do modelo toxicológico inicial vem trazer, também, para primeiro plano os trabalhadores que se querem manter sujeitos do seu trabalho e atores das suas condições de trabalho. Abre-se, assim, um campo de investigação e de intervenção que não deixa na sombra o papel determinante do trabalho enquanto agente de saúde, isto é, no desenvolvimento e na construção da 
saúde. Um campo ainda mais extenso quando se aborda a manutenção em atividade daqueles que, cada vez em maior número, vivem com uma saúde frágil, ou ainda daqueles que vivem "sem trabalho" à margem do mercado de emprego. Neste domínio, a produção científica é ainda largamente insuficiente, apesar de a psicopatologia do trabalho ter legado uma tradição considerável no que toca às funções psicológicas e sociais do trabalho no restabelecimento e desenvolvimento da saúde psíquica.

2.7. A renovação das abordagens impõe-se também em virtude dos efeitos das transformações do trabalho nos contextos sociais, económicos e políticos de cada um dos diferentes países. A globalização económica veio, na verdade, questionar as condições do exercício do poder soberano do Estado em conjunturas nacionais politicamente diferentes. Com efeito, o comércio internacional, a livre circulação de capitais e, concomitantemente, o desenvolvimento dos mercados financeiros internacionais, tendem a interferir e a influenciar o exercício do poder dos Estados. Ora, a liberalização mundial dos fatores de produção, tais como o trabalho e o capital, não se processa do mesmo modo nem com a mesma intensidade. Assim, se, por um lado, os fluxos migratórios são, hoje em dia, rigorosamente controlados em muitos países, a liberdade de circulação de capitais, por outro lado, é fortemente encorajada à escala global, apesar de em alguns países, como Cuba, continuar ainda, por razões diversas, a ser objeto de práticas restritivas.

\section{A continuação dos debates}

Este evento científico permitiu reunir um grande número de investigadores e de profissionais ligados à problemática da saúde no trabalho, empenhados na troca de experiências e no(s) diálogo(s) entre várias abordagens disciplinares (psicologia do trabalho, ergonomia, sociologia, ciências da gestão, ciências da educação, direito, filosofia, etc.). Ao submeter a debate o(s) conceito(s) de saúde - entendida nas suas dimensões física, psíquica e social - e o conceito de trabalho, bem como as interações entre ambos, pretendeu-se contribuir para uma produção científica internacional que, por ter frequentemente como referência o mundo anglófono, tende a subestimar o carácter inovador da investigação e das intervenções levadas a cabo em regiões hispanófonas e lusófonas.

17 Sem dúvida que o desafio vai continuar, desde logo porque o segundo Simpósio FrançaAmérica Latina, irá realizar-se em João Pessoa, no Brasil, em finais de outubro de 2020, terá como tema central Trabalhar : para fazer o quê ? (https://eitajp.wixsite.com/jp2020).

\section{NOTAS}

1. Société d'Ergonomie de Langue Française, Association Française de Psychologie du travail et des Organisations, Instituto National de Salud de los Trabajadores, Red Iberoamericana de Promoción de la Seguridad Integral en el Trabajo, Programa Iberoamericano de Ciencia y 
Tecnología para el Desarrollo, Réseau de Recherche de Psychologie du Travail et des Organisations, Groupe d'Etudes Sur le Travail et la Souffrance au travail.

2. Está a ser finalizada uma obra colectiva, em três línguas, composta por 24 textos resultantes das comunicações apresentadas durante o Simpósio. Vai ser publicada em 2020 pela editora L'Harmattan, em versão electrónica e em papel, com o título: Subjectivité et travail. Construction d'un nouveau paradigme de la santé au travail [Subjectividade e trabalho. Construção de um novo paradigma de saúde no trabalho].

\section{AUTORES}

\section{DOMINIQUE LHUILIER}

Équipe Psychosociologie du travail et de la formation, Centre de recherche sur le travail et le développement, Conservatoire National des Arts et Métiers [Grupo de Psicologia do Trabalho e da Formação, Centro de Investigação do Trabalho e do Desenvolvimento, Conservatório Nacional das Artes e Ofícios]. 41 rue Gay Lussac, 75005 Paris, France.

dominique.lhuilier@lecnam.net

\section{MARIANNE LACOMBLEZ}

Centro de Psicologia da Universidade do Porto, Faculdade de Psicologia e Ciências da Educação, Universidade do Porto. Rua Alfredo Allen, 4200-135, Porto, Portugal.

lacomb@fpce.up.pt 